\title{
Electrical streaming potential precursors to catastrophic earthquakes in China
}

\author{
Yu-Lin Zhao, Bi-Ru Zhao and Fu-Ye Qian \\ Institute of Geophysics, State Seismological Bureau, Beijing, P.R. China
}

\begin{abstract}
The majority of anomalies in self-potential at 7 stations within $160 \mathrm{~km}$ from the epicentre showed a similar pattern of rapid onset and slow decay during and before the $M 7.8$ Tangshan earthquake of 1976. Considering that some of these anomalies associated with episodical spouting from boreholes or the increase in pore pressure in wells, observed anomalies are streaming potential generated by local events of sudden movements and diffusion process of high-pressure fluid in parallel faults. These transient events triggered by tidal forces exhibited a periodic nature and the statistical phenomenon to migrate towards the epicentre about one month before the earthquake. As a result of events, the pore pressure reached its final equilibrium state and was higher than that in the initial state in a large enough section of the fault region. Consequently, local effective shear strength of the material in the fault zone decreased and finally the catastrophic earthquake was induced. Similar phenomena also occurred one month before the M 7.3 Haichen earthquake of 1975 . Therefore, a short term earthquake prediction can be made by electrical measurements, which are the kind of geophysical measurements most closely related to pore fluid behaviors of the deep crust.
\end{abstract}

Key words self-potential - precursors to earthquakes - coseismic effects - pore pressure - streaming potential

\section{Introduction}

The phenomena that the filling of a reservoir or injection of water into the underground may induce an earthquake are well known to seismologists. However, at the place where there is neither reservoir nor injection of water it was little reported that the increase in pore pressure may trigger a strong earthquake. When a sudden movement of fluid takes place in a fault zone an electrical streaming potential would be generated. Coseismic variation and precursor in self potential, which is called

Mailing address: Dr. Yu-Lin Zhao, Institute of Geophysics, State Seismological Bureau, No. 5 Minzuxueyuan Nanlu, Haidian District, Beijing 100081, P.R. China; e-mail: ZYL@cdsndmc.css.gov
SP for short, during and before the Tangshan earthquake and from the SP data the inference that the Tangshan earthquake was induced by the increase in pore pressure is reported as follows.

\section{Data}

The self-potential variations reported in this paper were measured across receiving dipoles used to monitor electrical resistivity variations when an artificial electric field is built up through transmitting dipoles (Zhao and Qian, 1994). The electrodes are of lead, which are chemically relatively stable and also associated with small polarization potentials. The terrain was smooth with no evident difference in elevation $(<2 \mathrm{~m})$ between the electrodes spaced a few hundreds metres apart. The two measuring channels were formed by two pairs of electrodes buried at a depth of 1.5-2 $\mathrm{m}$ along the orientations of magnetic N-S and E-W, so that 
the seasonal freeze (freezing depth of about $0.8 \mathrm{~m}$ ) or thaw in the surface layer had no significant effect on the observation. The groundcontacting resistance is from a few tens to one or two hundred ohm. The electrodes were connected with a d. c. $\mathrm{mV} / \mathrm{m}$ of high input impedance ( $8 \mathrm{M} \Omega$, the DDC-2 type with electro-automatic compensation) through the conducting wires that were covered with good insulating material to avoid interference from electricity leakage. The errors due to instrumentation were no more than $1.5 \%$ of the measuring range used. Calibration was made through a standard potential difference meter before and after the earthquake and no systematic deviation was found with the measuring precision. The interferences from industrial stray current or the induction in wires when they were swinging with the wind and crossing the magnetic lines of force were usually no more than $0.2-1.0 \mathrm{mV} / \mathrm{km}^{-1}$. The polarities at different stations had been standardized in order to make a comparison of the directions of change in a self-potential. With this standardization an increase in potential difference in the E-W channel meant that the potential at the west electrode increased in relation to the east electrode while an increase in the N-S channel meant that the potential at the south electrode increased in relation to the north electrode.

The daily means of the day field (from no fewer than six measurements made every day) were chosen as original data in the present study, so that no consideration of the interference from telluric current etc. with periods shorter than $24 \mathrm{~h}$ is needed. In order to estimate the background noise the data recorded one month before appearance of the variation with half-month period were used to calculate the standard deviations for these self-potential measurements. The deviations are $1.36 \mathrm{mV} /$ $\mathrm{km}^{-1}$ for the E-W channel and $1.56 \mathrm{mV} / \mathrm{km}^{-1}$ for the N-S channel at Xiji (XJ) station, 0.50 $\mathrm{mV} / \mathrm{km}^{-1}$ for the E-W channel at Tanggu (TG) station and $22.0 \mathrm{mV} / \mathrm{km}^{-1}$ for E-W channel at Baodi (BD) station. Such standard deviations can also be used to estimate the normal background noise at these stations because duration periods of analysed anomalies are shorter than one month. The polarized potential, at the electrodes buried for a long period, for interference is likely to vary with groundwater level and some meteorological conditions, e.g. snow or rain. Therefore we made a comparison of the data with the records for the same periods in previous years to identify such interferences. The comparison showed that the change in electric field with half-month period had never happened before. Comparison with information about precipitation and irrigation in 1976 showed that the pre-earthquake variation of half-month period of the electric field did not have any links with such interference factors.

The fact that the change in self-potential correlated to the tidal force $M S_{f}$ appeared in channels which were mutually independent at Xijin (XJ) station further indicates that such a change was not caused by the variations due to the polarization potential at elecrodes, but due to the electrical field in the Earth (Zhao and Qian, 1994). The pre-earthquake change in self-potential with half-month period had been seen only at some stations although there were altogether seven stations within $120 \mathrm{~km}$ of the epicentre of the main shock. Only some periodical variations with amplitudes a few times greater than the usual background noise were detected at certain stations. Those fluctuations were not regarded to be due to a change in telluric current and did not appear to be related to rainfall or instrumental problems.

\section{Coseismic effect in SP}

The coseismic effect is very convincing evidence for accepting preseismic variation as a precursor to the earthquake. So first, the coseismic effects in SP during the $M 7.8$ Tangshan earthquake of 1976 will be shown.

Coseismic changes in the SP were recorded at the stations TG, XJ, QG and QX during the earthquake (fig. 1). In the meanwhile, coseismic effects in underground water level were also recorded at many wells, such as TSS, SGL and so on. Anomalies in the form of a step voltage were evident during the earthquake as shown by fig. 2 where the curves are the daily means. It can be seen that a noticeable drop in 


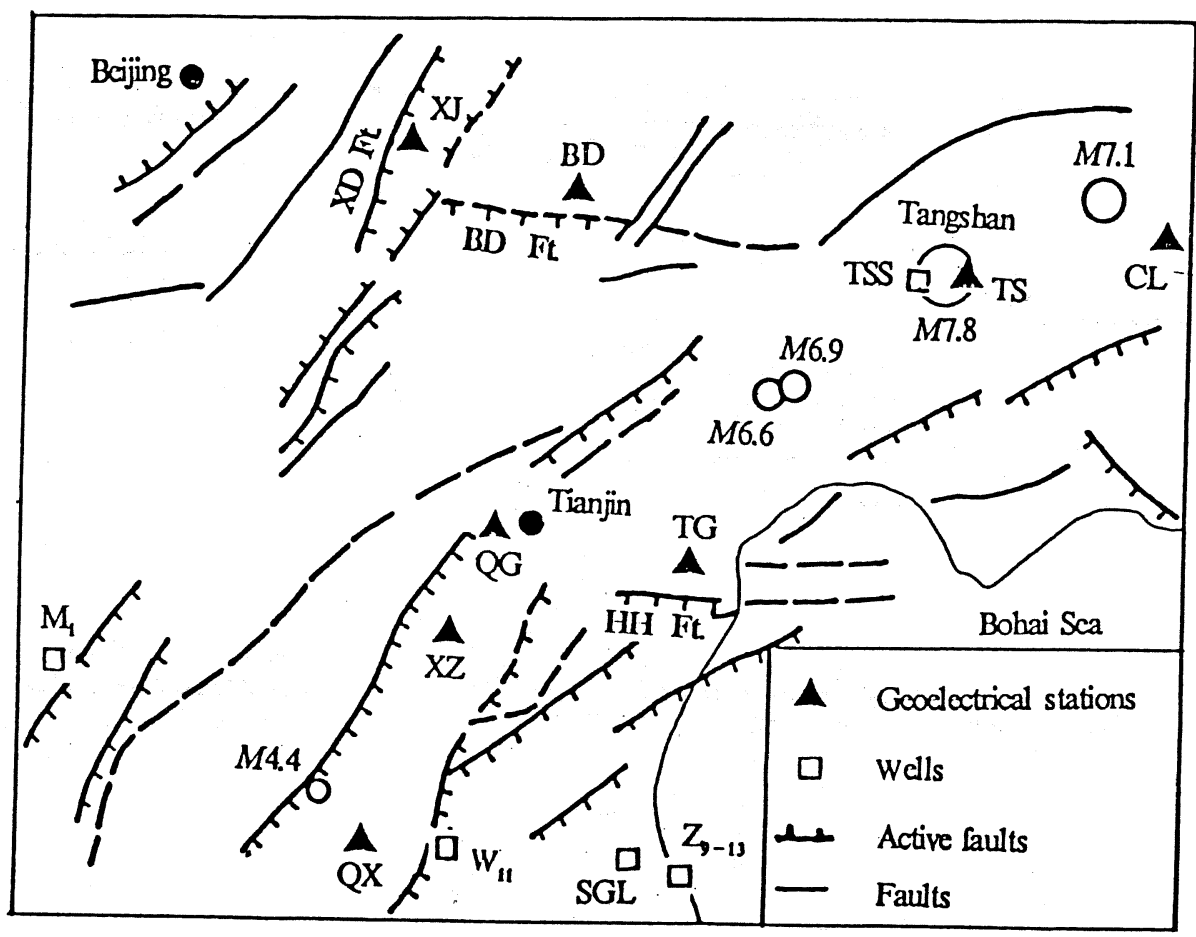

Fig. 1. Distribution of self-potential stations, oil and water wells and faults.

SP appeared both in the N-S channel at the station TG and in the E-W channel at the XJ station during the main shock. And a noticeable rise in SP occurred both in the E-W channel at the station QG and in the N-E channel at the station QX during the earthquake. The epicentral distance is $60,120,110$ and $160 \mathrm{~km}$ respectively. The amplitudes of the coseismic effect are much greater than standard deviations of measurements at the stations respectively. For understanding the causative mechanism for the anomalies in SP, the coseismic rises in underground water level recorded at the wells TSS and SGL are also shown in fig. 2. The distance from the epicentre to these wells are 1.5 and $85 \mathrm{~km}$ respectively. It can be seen from this figure that all coseismic effects in SP show a similar pattern of rapid onset and slow decay, suggestive of a step-input diffusion process (Corwin and Morrison, 1977).

\section{Precursors in SP}

\subsection{Description of variations}

When correlations of possible precursors to earthquakes are attempted the most important factor is to define the nature of the precursor and carefully to remove noise. In terms of the specific pattern of rapid onset and slow decay a precursor in $\mathrm{SP}$ can be indentified from noise. Anomalies of the specific pattern of rapid onset and slow decay were recorded at stations CL, BD, TG, QG and XZ about one month before the Tangshan earthquake (fig. 3). An anomalous pattern of slow decay and sudden step were recorded at stations XJ and QX. The distance from the station CL to the main shock is $70 \mathrm{~km}$, but to the $M 7.1$ greatest aftershock on the same day is only $35 \mathrm{~km}$. The epicentral distance to other stations is $80,80,110$, 


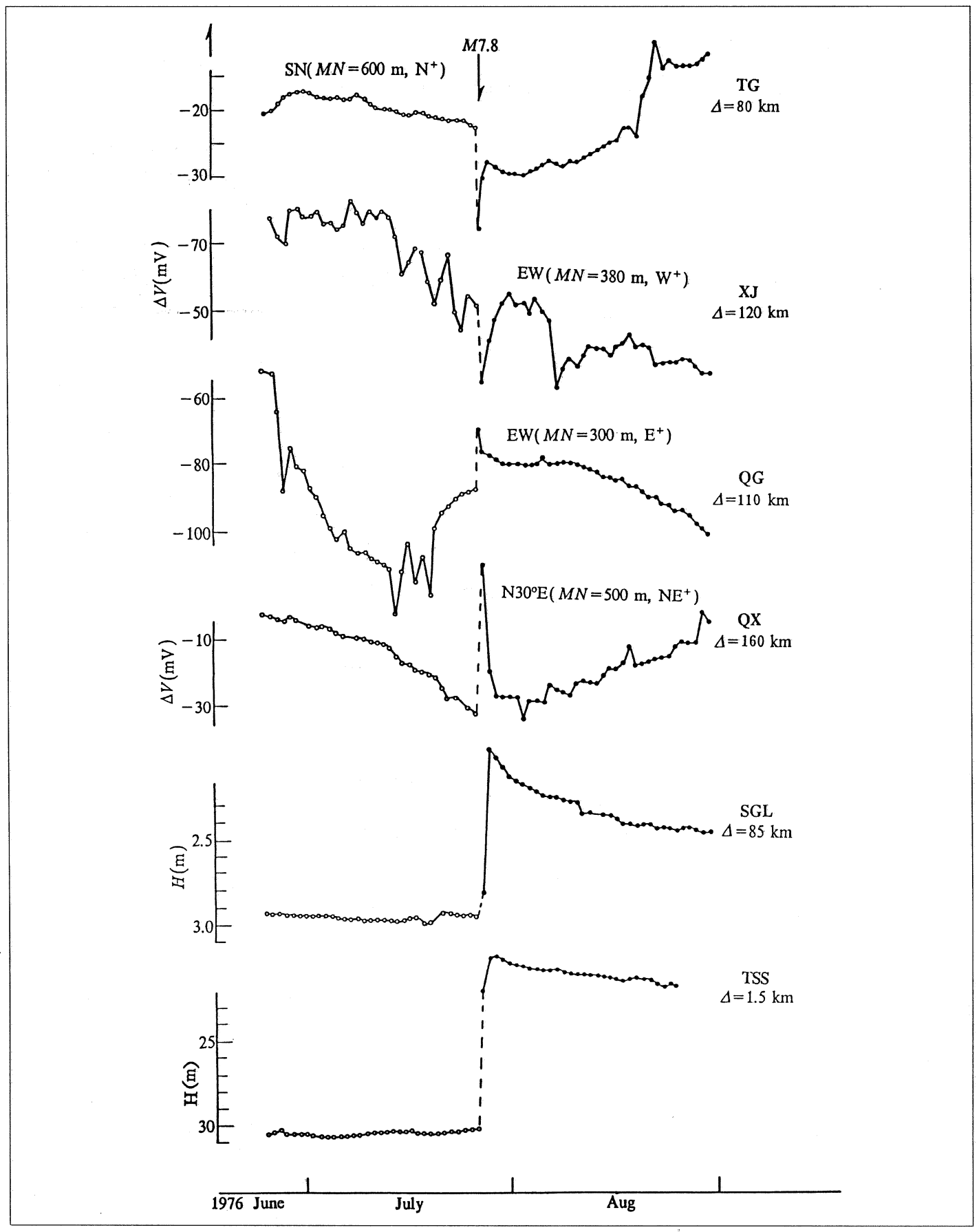

Fig. 2. Coseismic effects in self-potential and underground water level of the $M 7.8$ Tangshan earthquake of 1976 . 


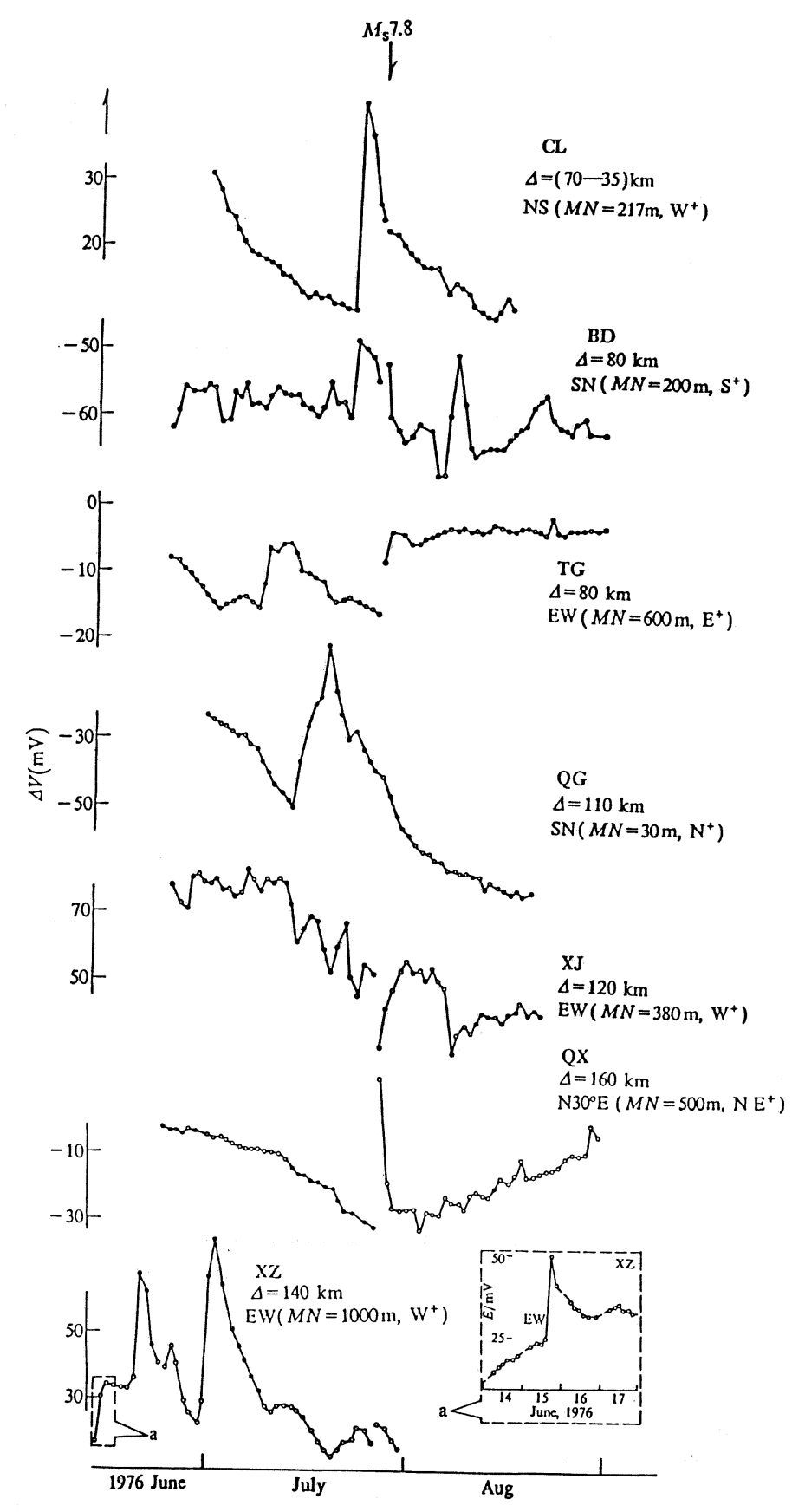

Fig. 3. The short-term precursor in self-potential of the $M 7.8$ Tangshan earthquake of 1976. 

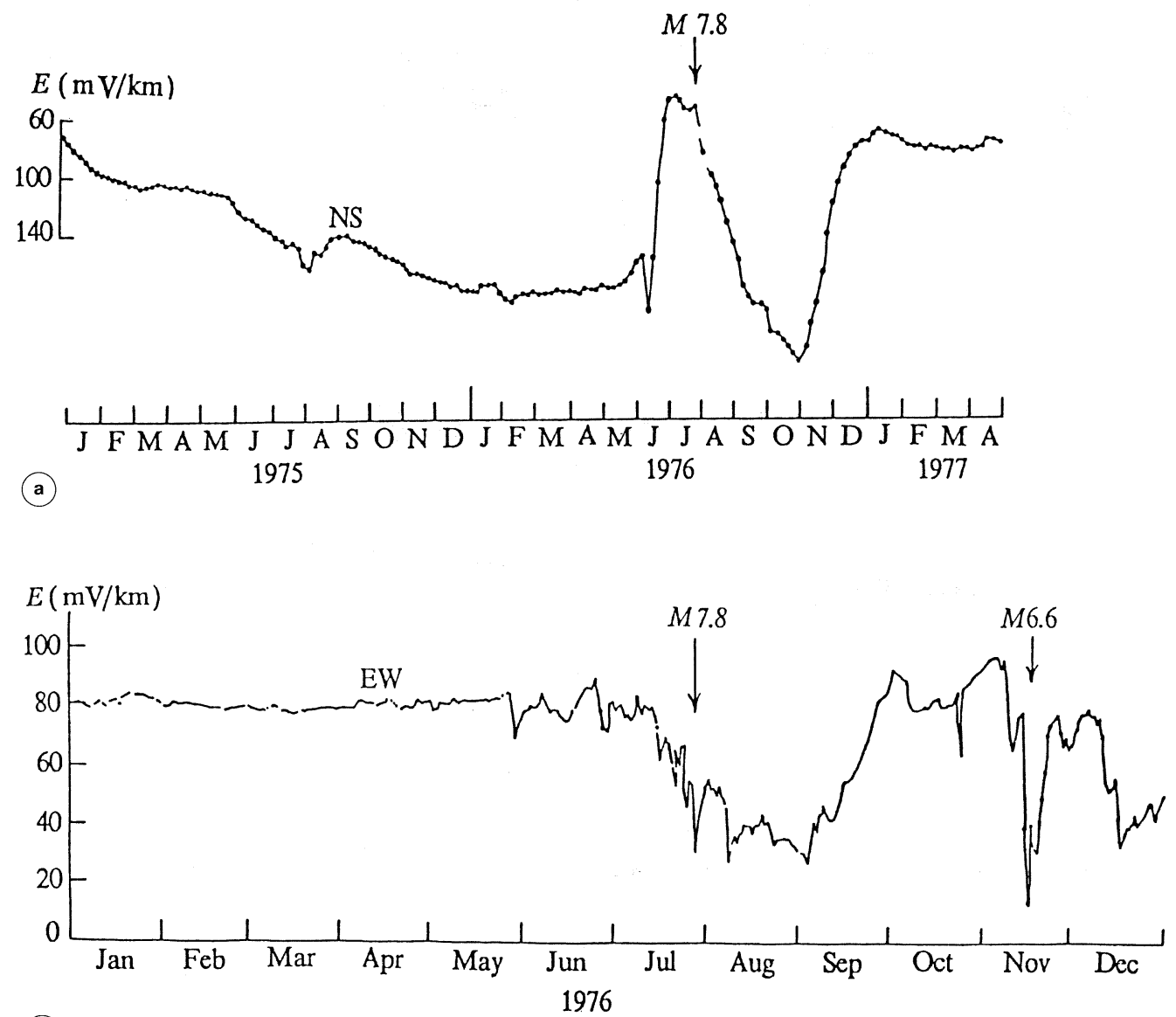

(b)

Fig. 4a,b. Self-potential observed at the station XJ in the N-S channel from January, 1975 to April, 1977 (a); in the E-W channel in 1976 (b).

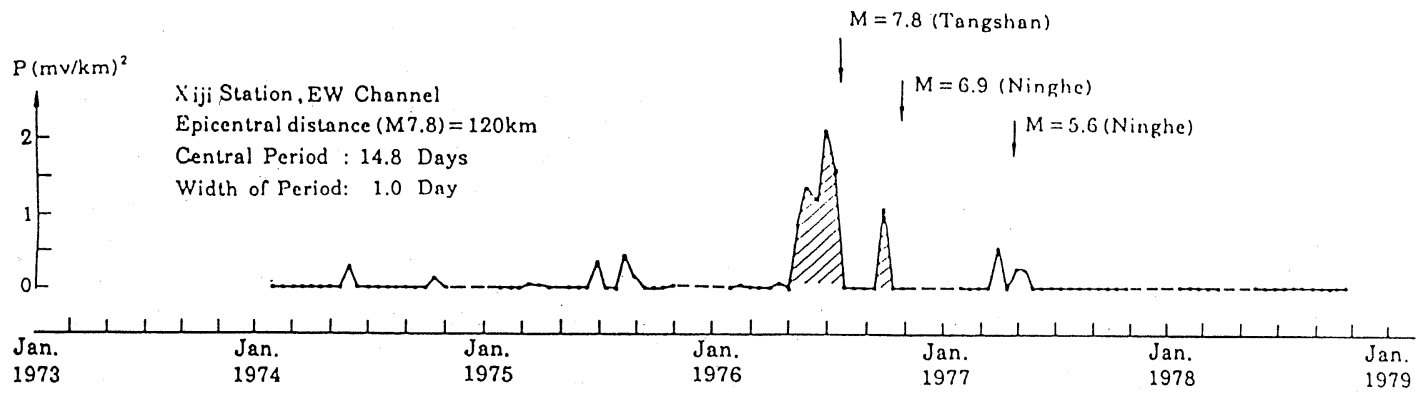

Fig. 5. The power spectrum anomaly of SP response to the tidal force $M S_{f}$. 
120,140 and $160 \mathrm{~km}$ respectively. The amplitudes of the precursor in SP are much greater than the standard deviations of measurements at the stations respectively. It can be seen from fig. 4a,b in which SP data for over two years are presented that the anomaly just two months before the mainshock was larger than the background fluctuations and hence statistically significant. In order to check phenomena, the power spectrum density (fig. 5) in self-potential of the 14.8 day period was quantitatively analysed. It can be seen that anomalies in power spectra $4 \geq 6$ times the usual background noise appeared only two months before the main shock.

\subsection{The increase in pore pressure}

The pore pressure in borehole $\mathrm{Z}_{9-13}$ (Zhang and Zhao 1983) whose epicentral distance is $130 \mathrm{~km}$ and the SP variation observed at the station QG are shown in fig. 6 to demonstrate the relation between the self-potential and pore pressure. It can be seen that synchronous variations in both the fluid pressure and the self-potential were evident from 17 June to early September 1976. This indicates that the precursor in SP may be due to streaming potential

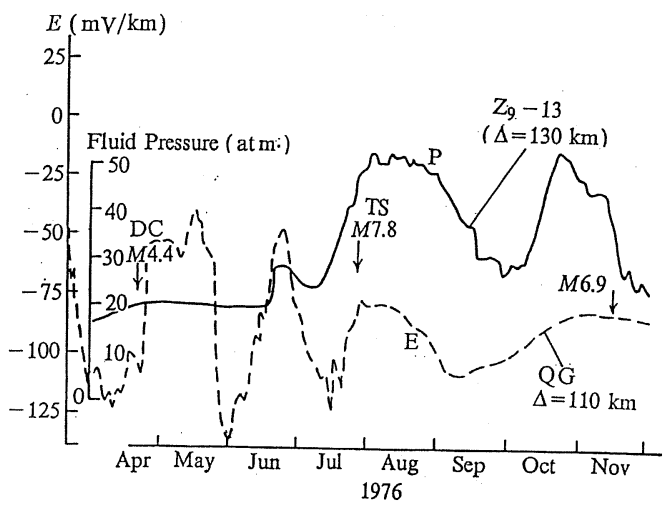

Fig. 6. Comparison between the variations in SP observed at the station QG and the changes in the fluid pressure measured at the casing head of the borehole $\mathrm{Z}_{9-13}$ before and after the Tangshan earthquake. generated by the sudden movement of fluid from the high-pressure compartment to the low-pressure compartment in the fault zone. It is noticeable that rises in fluid pressure have some thing to do with the phase of the moon.

In order to make the correlation with the moon phases more clear the residual curve, representing the differences between the running average values of 15-day interval and daily mean values of fluid pressure is plotted in fig. 7. It can be seen that there is one complete oscillation of a half-month period from June 12 (the full moon) of June 27 (the new moon) and that the SP minima 1 \#, 2 \# and 3 \# occurred correlate well with the times of the full or new moon.

\subsection{Oil blowouts}

Two oil blowouts took place at the borehole $\mathrm{W}_{11}$ which is located $125 \mathrm{~km} \mathrm{S-E}$ of the main shock and suddenly happened on 16 June and a half month later i.e. on 30 June, 1976 which also had some thing to do with the phase of the moon and showed a half-month period. It is noticeable that the main shock of the Tangshan earthquake occurred at $3 \mathrm{~h} 42 \mathrm{~min}$ in 28 July, 1976 which had some thing to do with the new moon at $9 \mathrm{~h} 39 \mathrm{~min}$ in 27 July, 1976. The occurrence of the main shock delayed only $18 \mathrm{~h}$ after the time of the new moon.

\subsection{Periodicity of precursors and the triggering tidal forces}

The beginning times of the SP precursors are listed at the right column of table I. It can be seen that the periodic nature in SP are evident two months before the great $M 7.8$ Tangshan earthquake.

The fact that these events such as oil blowout, earthquake, the increase in pore pressure, the beginning of SP precursor and the coseismic effects both in SP and in underground water level have some thing to do with the phase of the moon shows the periodicity caused by tidal forces. 
Fluid Pressure

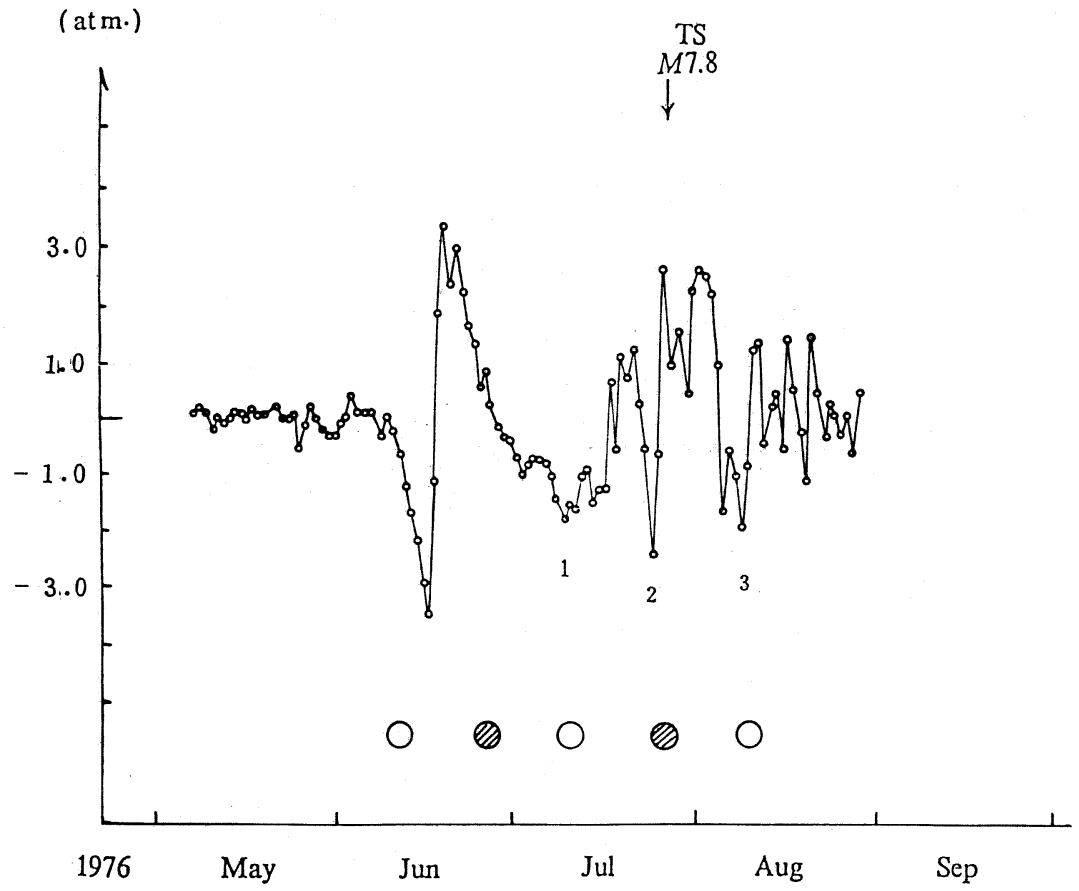

Fig. 7. The residual curve, representing the differences between the running average values of 15-day intervals and daily mean values of the fluid pressure.

Table I. The SP precursors in relationship with the phase of the moon and its periodicity.

\begin{tabular}{|c|c|c|c|}
\hline Phase of the moon & $\begin{array}{l}\text { Oil blowout or } \\
\text { earthquake }\end{array}$ & $\begin{array}{l}\text { Pore pressure and } \\
\text { water level }\end{array}$ & SP \\
\hline June $12,12 \mathrm{~h}$ full moon & $\begin{array}{l}\text { June } 16, \text { oil blowout } \\
\text { from the borehole } W_{11} \\
(\Delta=125 \mathrm{~km})\end{array}$ & $\begin{array}{l}\text { June } 17 \text {, increasing from } \\
20 \text { atm to } 28 \mathrm{~atm}\end{array}$ & $\begin{array}{l}\text { June } 15, \mathrm{XZ} \\
\text { SP rapid onset }\end{array}$ \\
\hline June $27,22 \mathrm{~h}$ new moon & $\begin{array}{l}\text { June } 30-\text { July } 1 \text {, oil } \\
\text { blowout from the bore- } \\
\text { hole } \mathrm{W}_{11}\end{array}$ & & $\begin{array}{l}\text { June } 30, \mathrm{XZ} \\
\text { SP minimum }\end{array}$ \\
\hline July $11,21 \mathrm{~h}$ full moon & & $\begin{array}{l}\text { July } 10 \text {, increasing of } \\
\text { the pore pressure }\end{array}$ & $\begin{array}{l}\text { July } 9, \text { TG } \\
\text { SP minimum } \\
\text { July } 15, \text { QG } \\
\text { SP minimum }\end{array}$ \\
\hline $\begin{array}{l}\text { July } 19,14 \mathrm{~h} \text { last quarter } \\
\text { of the moon }\end{array}$ & $\begin{array}{l}\text { July } 21 \text {, oil blowout } \\
\text { from the borehole } M_{1} \\
(\Delta=180 \mathrm{~km})\end{array}$ & & $\begin{array}{l}\text { July } 23, \mathrm{CL} \\
\text { SP minumum }\end{array}$ \\
\hline July $27,9 \mathrm{~h}$ new moon & $\begin{array}{l}\text { July 28, the } M 7.8 \\
\text { earthquake }\end{array}$ & $\begin{array}{l}\text { July } 28 \text {, TSS, SGL... the } \\
\text { sudden rises of water } \\
\text { level or water blowout }\end{array}$ & $\begin{array}{l}\text { July } 28, \\
\text { TG, XJ, QG, QX } \\
\text { SP rapid onset }\end{array}$ \\
\hline
\end{tabular}




\subsection{The migration of precursor towards the epicentre}

If the duration time is $t$, which is the period from the commencement of the SP precursor to the earthquake and $\Delta$ is the epicentral distance of the station where the precursor occurred, the following empirical relation exists:

$$
t=0.88+0.123 \Delta
$$

with a correlation coefficient $r=0.68$ (fig. 8). It can be seen that statistically, precursors occurred first at stations more distant to the epicentre and later at closer stations, i.e., the SP precursors migrated towards the epicentre one month before the Tangshan earthquake.

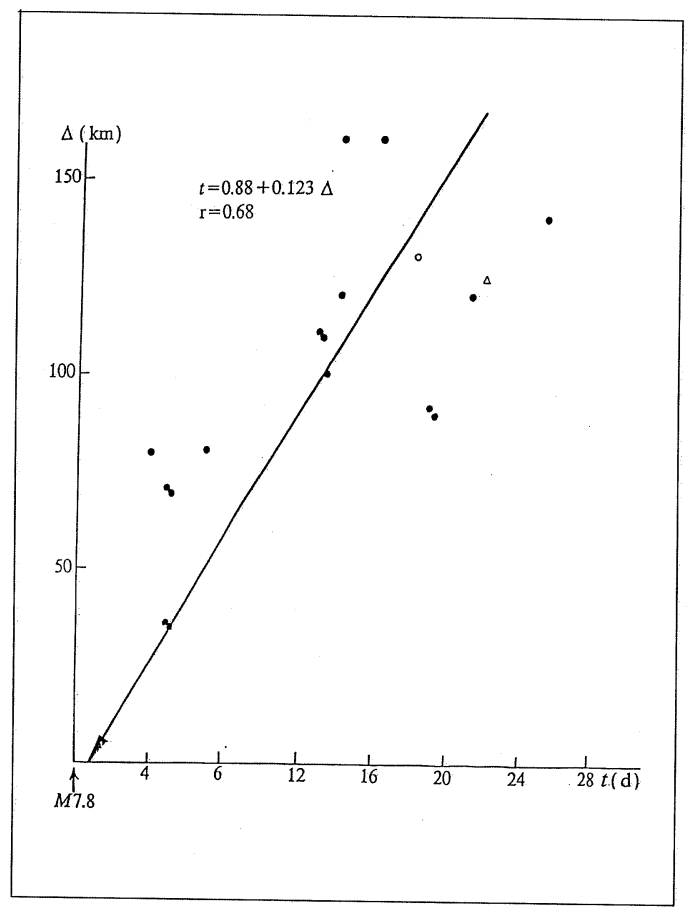

Fig. 8. The statistical curve that events such as onsets in $\operatorname{SP}(1)$, oil blowouts $(\Delta)$ and the increase in pore pressure (O) migrating towards the epicentre one month before the Tangshan earthquake.

\section{Discussion}

\subsection{Streaming potential}

The correlation between the coseismic effects or precursors in SP and either the oil blowouts from boreholes or the increases in fluid pressure in the wells is evident. Therefore, the observed coseismic effects and precursors in SP are streaming potential generated by the sudden flow of groundwater from the high-pressure compartment to the low-pressure compartment. The equation governing the streaming potentials is

$$
\Delta V=-\frac{\varepsilon \zeta}{\eta \sigma} \Delta P=C \Delta P
$$

where $\Delta V$ is the electrical streaming potential difference generated, $\Delta P$ is the magnitude of the pore pressure difference driving the flow. $C$ is coupling coefficient. $\zeta$ is the zeta potential and $\sigma, \varepsilon, \eta$ are the conductivity, the dielectric constant and the viscosity of the fluid respectively. Nourbehecht (1963) showed that the important parameter in the Earth is the difference $(\Delta C)$ of coupling coefficients between buried zones. The typical values for $\Delta C$ are of the order of $\pm 5 \mathrm{mV} / \mathrm{atm}$ to $\pm 10 \mathrm{mV} / \mathrm{atm}$ (Morgan et al., 1989).

\subsection{Earthquake triggering mechanism}

Both coseismic and preseismic anomalies in self-potential probably have relations with distributed strike-slip systems which consist of dense sets of parallel or sub-parallel NNE-, NE- or NW-trending faults in North China (Nur and Ron, 1987; Wang et al., 1978). In a crustal environment, the interconnected fluid phase dominates the electrical conductivity. The Tangshan main shock and most of its aftershocks were related closely to the resistive upper crust (Qin et al., 1991).

This would seem to imply that the fluid porosity becomes very small, and one has to consider the possibility that this phase will not remain interconnected and it is very likely that unusual fluid pressure systems can exist in this region. Although crustal fault zones that have been brought up to the surface apparently show 
evidence of various amounts of fluid flow in these zones (Mei et al., 1982; Wang, 1985; Roeloffs, 1987).

During shearing, the fluid in the fault zone was separated by walls of very low permeability into compartments of various sizes and unequal pore pressure (Byherlee, 1993). When the wall between two of these compartments is ruptured usually with the triggering of tidal forces, an electrical streaming potential or oil blowout from a borehole, if there is one, would be generated by the sudden movement of fluid from the high-pressure compartment to the low-pressure compartment.

A similar process took place periodically many times in the fault zone and statistically ruptures took place first at walls more distant from the epicentre and later at nearer walls.

When the pore pressure in the last two compartments reached its final equilibrium state the average pore pressure would be higher than the average initial pressure in these two compartments which were a large enough segment of the fault zone. The average effective shear strength of the material decreased in the fault zone and the earthquake occurred.

\section{Concluding remarks}

1) Both coseismic and preseismic anomalies in self-potential were observed at 4-7 stations within $160 \mathrm{~km}$ to the epicentre during and before the $M 7.8$ Tangshan earthquake of 1976. The majority of anomalies show a similar pattern of rapid onset and slow decay, suggestive of a step-input diffusion process. In terms of the fact that anomalies have something to do with the oil blowout and the increase in pore pressure in boreholes or water wells, the anomalies are caused by streaming potentials generated by sudden movements of ground water. The anomalies show periodicity and the statistical phenomenon that the precursors in SP took place first at stations more distant from the epicentre and later at closer stations one month before the earthquake. According to the specific pattern and periodicity, the anomalies could be distinguished from noise. A similar phenomenon was also observed during and before the $M 7.3$ Haicheng earthquake of 1975. This is only one part of the story.

2) On the other hand, the increase in pore pressure decreased the local effective shear strength of the material in the fault zone and induced the strong earthquake. So a short-term earthquake prediction can be made by means of the streaming potential precursors.

\section{Acknowledgements}

This work was sponsored by the National Natural Science Foundation of China and by the Chinese Joint Seismological Science Foundation.

\section{REFERENCES}

BYERLEE, J. (1993): Model for episodic flow of high-pressure water in fault zones before earthquakes, Geology, 21, 303-306.

CorwIN, R.F. and H.F. MORRISON (1977): Self-potential variations preceding earthquakes in Central California, Geophys. Res. Lett., 4 (4), 171-174.

MeI, S.R., C.H. Hu, C.Z. ZHU and J. MA (Editors) (1982): The 1976 Tangshan Earthquake, Beijing: Seismological Press, 246-270.

Morgan, F.D., E.R. Williams and T.R. MADDEN (1989): Streaming potential properties of westerly granite with applications, J. Geophys. Res. 94 (B9), 12449-12461.

NOURBEHECHT, B. (1963): Irreversible thermodymamic effects in inhomogeneous media and their applications in certain geoelectric problems, Ph.D. Thesis, Mass. Institute of Technology, Cambridge.

NuR, A. and H. Ron (1987): Kinematics and mechanics of tectonic block rotations: a review, in Proceedings of Workshop 37, Physical and Observational Basis for Intermediate-Term Earthquake Prediction, Menlo Park, California, vol. 1, 797-823.

Qin, X., L.B. Pedersen, Y. Zhao, P. Zhang, F. Oian, W. QIAN, Z. LI and J. DU (1991): Conductivity structure of crust in the Tangshan seismic area and the possibility of exploring potential seismic sources by magnetotelluric method, Acta Seismol. Sinica, 13 (3), 354-363.

RoElOFFS, E.A. (1987): Hydrologic precursors: a critical review, in Proceedings of Workshop 37, Physical and Observational Basis for Intermediate-Term Earthquake Prediction, Menlo Park, California, vol. 1, 104-140.

WANG, C.M. (1985): Ground-water studies for earthquake prediction in China, Pure Appl. Geophys., 122, 215-217.

WANG, Z., D. Zsheng, S. Chen, Y. WU and G. LiU (1978): On fault displacement in the Peking district, Acta Geophys. Sinica, 21 (4), 269-277.

ZHANG, D. and G. ZHAO (1983): Anomalous variations in oil wells distributed in the Bohai by oil field before and after the Tangshan earthquake of 1976 (in Chinese), Acta Seismol. Sinica, 5 (3), 360-369.

ZHAO, Y. and F. QIAN (1994): Geoelectric precursors to strong earthquake in China, Tectonophysics, 233, 99-113. 